Revista Estudios, (37), 2018.

Diciembre 2018-Mayo 2019

V Sección: Educación e identidad
ISSN 1659-3316

Argüello Scriba Sol

Regueyra Edelmann María Gabriela

\title{
Cultura académica, retórica y lectoescritura en la universidad
}

\author{
Sol Argüello Scriba \\ Universidad de Costa Rica, Costa Rica \\ solarcr1@gmail.com \\ https://orcid.org/0000-0002-4485-1195
}

María Gabriela Regueyra Edelmann

Universidad de Costa Rica, Costa Rica

gabriela.regueyra@gmail.com

https://orcid.org/0000-0001-5544-1311

Recibido: 30 de junio de 2018

Aceptado: 6 de agosto de 2018

Resumen: El artículo plantea la preocupación por las limitaciones que presenta la población estudiantil universitaria en la comprensión lectora y la producción escrita, desarrolla la propuesta de que cada disciplina es una cultura particular con su objeto de estudio, sus códigos lingüísticos, su forma de estructurar el pensamiento y de realizar propuestas. Insta a la población docente de cada carrera a asumir la responsabilidad de brindar las herramientas teórico metodológicas necesarias para aprender los contenidos de la materia, su respectiva alfabetización (aprender a leer y escribir) y el desarrollo de un discurso crítico. Propone que la retórica aporta bases teóricas y posibles métodos en el arte de escribir y comprender textos, desde los planteamientos clásicos griegos, luego pasando por los estudios lingüísticos del lenguaje y la noción bajtiniana de los distintos géneros discursivos, así como la lingüística moderna con el empleo y comprensión del discurso.

Palabras clave: Retórica; comprensión lectora; escritura académica; cultura disciplinar

\section{Academic culture, Rethoric and literacy in the university}

La Revista Estudios es editada por la Universidad de Costa Rica y se distribuye bajo una Licencia Creative Commons Atribución-NoComercial-CompartirIgual 3.0 Costa Rica. Para más información envíe un mensaje a 
Abstract: The article propose the concern about the limitations that the university student population presents in reading comprehension and written production, develops the proposal that each discipline is a particular culture with its object of study, its linguistic codes, its way of structuring thought and making proposals. Urges the teaching population of each career to take responsibility for providing the theoretical methodological tools necessary to learn the content of the subject, their respective literacy (learning to read and write) and the development of a critical discourse. proposes that the rhetoric provides theoretical bases and possible methods in the art of writing and understanding texts, from the classical Greek approaches, then going through linguistic studies of language and the Bajtinian notion of the different discursive genres, as well as modern linguistics with the employment and understanding of discourse.

Key Words: Rhethoric; reading comprehension; university writing; disciplinary culture

Introducción

La población docente se enfrenta, hoy en día, a uno de los mayores retos: la pobre comprensión de la literatura pertinente a sus carreras por parte de la población estudiantil y las dificultades para la realización de trabajos escritos, situación que afecta de manera negativa la permanencia y la conclusión exitosa de los estudios universitarios.

El desarrollo de la lectoescritura, en cada comunidad académica, está entrelazada con el acercamiento a su objeto disciplinar y al lenguaje propio que le da sentido comunicativo. De ahí que es desde cada disciplina que se debe construir la manera de enseñar a leer y a escribir en su propia cultura académica.

La población docente universitaria conoce su objeto de estudio disciplinar pero carece de la formación en el área de la comprensión lectora y la expresión escrita, por lo que las autoras de este artículo, preocupadas por esta situación, nos hemos propuesto comprender las dimensiones del problema desde referentes teóricos y empíricos que nos permitan construir las bases para desarrollar

La Revista Estudios es editada por la Universidad de Costa Rica y se distribuye bajo una Licencia Creative Commons Atribución-NoComercial-CompartirIgual 3.0 Costa Rica. Para más información envíe un mensaje a 
Revista Estudios, (37), 2018.

Diciembre 2018-Mayo 2019
ISSN 1659-3316

Argüello Scriba Sol

Regueyra Edelmann María Gabriela

estrategias y fortalecer la habilidad de lectura y escritura en la población estudiantil.

Nuestro primer acercamiento a este tema nos hizo comprender que el tema de la lectoescritura ha sido abordado desde procesos integrales, afectados por diversos factores como el entorno económico, social, educativo, familiar entre otros, y también desde el desarrollo de las habilidades y destrezas cognitivas donde los campos como la psicopedagogía, la lingüística, la filología, la didáctica, entre otras disciplinas, aportan para su comprensión y abordaje. Esto nos ha llevado a la ruptura de nuestros propios mitos, reflexiones sintetizadas en el ensayo que titulamos "Superando mitos sobre la comprensión lectora en la población estudiantil universitaria". En el presente escrito compartimos algunas premisas teóricas y discusiones sobre los aportes de la retórica, desde sus orígenes hasta la actualidad, en la compresión del problema.

\section{La Universidad ¿una nueva cultura académica?}

La Universidad es sinónimo de conocimiento, discusión y reflexión que se rige por normas y valores propios; es un espacio para el estudio de los diversos objetos de conocimiento de cada una de las disciplinas que la integran, en fin donde se "cultivan"1 los diversos saberes ${ }^{1}$.

La población estudiantil que ingresa a la universidad se enfrenta a diversas "culturas académicas" que poseen su propio lenguaje y una manera particular de estructurar los textos, ajenos a las experiencias educativas y cotidianas anteriores. En la universidad la lectura y escritura, como lo señala la especialista en el tema

${ }^{1}$ Cultura, del latín Cultus, us: cultivo, campo cultivado y también cultura, educación (Diccionario Latino-Español, Español- latino VOX, 95)

Universidad, del latín universitas,-atis: universalidad, totalidad, el mundo, el universo (Diccionario Latino-Español, Español- latino VOX, 515)

\section{(C) $(\triangle \odot)$}

La Revista Estudios es editada por la Universidad de Costa Rica y se distribuye bajo una Licencia Creative Commons Atribución-NoComercial-CompartirIgual 3.0 Costa Rica. Para más información envíe un mensaje a revistaestudios.eeg@ucr.ac.cr. 
Revista Estudios, (37), 2018.

Diciembre 2018-Mayo 2019

ISSN 1659-3316

Argüello Scriba Sol

Regueyra Edelmann María Gabriela

Estienne, son herramientas fundamentales para apropiarse del conocimiento y de su contenido: "Leer y escribir en la universidad tiene como, finalidad la construcción y apropiación de conocimientos dentro de un campo determinado del saber" (Estienne, 2012, p.533).

Por lo que la población estudiantil universitaria se enfrenta a una serie de demandas distintas a las exigidas en el nivel educativo de secundaria, las cuales han sido abordadas por diversos autores, entre estos Carlino, quien detalla que:

La universidad suele esperar que los alumnos encuentren información por sí mismos, en tanto que los docentes de la enseñanza media tienden a exigir sólo lo que ha sido transmitido por ellos. El nivel superior requiere que los estudiantes analicen y apliquen el conocimiento impartido, mientras que la secundaria espera que sea reproducido. En la universidad se proponen distintas perspectivas acerca de un mismo fenómeno; por el contrario, la escuela media enseña que el saber es verdadero o falso. Para la universidad, el conocimiento tiene autores e historia; en cambio, los niveles educativos previos lo presentan de forma anónima y atemporal. Estas diferencias en la naturaleza atribuida al saber y en los usos que se exigen de éste configuran culturas particulares que se traslucen en métodos y prototipos de pensar y escribir. (Carlino, 2003, p. 410)

Como un proceso de aprendizaje a través de los diversos niveles de la educación formal primaria y secundaria, la comprensión lectora inicia con la comprensión literal pasando por la comprensión inferencial, hasta llegar al nivel crítico intertextual, estos dos últimos deben ser favorecidos y fortalecidos en la educación universitaria. Carvajal y otros autores (2010) definen estos niveles de la siguiente manera:

\section{(c) (†) (-)}

La Revista Estudios es editada por la Universidad de Costa Rica y se distribuye bajo una Licencia Creative Commons Atribución-NoComercial-CompartirIgual 3.0 Costa Rica. Para más información envíe un mensaje a 
1.0 Nivel literal: en el que el estudiante no requiere ir más allá de lo que el texto explícito plantea.

2.0 Nivel inferencial: este le implica al estudiante realizar interpretaciones, inferencias, abstracción es, lanzar hipótesis.

3.0 Nivel crítico intertextual: le implica al estudiante relacionar el material de lectura con sus saberes previos, contextualizar el texto, establecer relaciones de intertextualidad y asumir una posición crítica. (Carvajal et al., 2010, p.135)

El abordar la lectoescritura en la universidad favorecerá la permanencia y la graduación de la población estudiantil, ya que coadyuvará con el aprendizaje, el rendimiento académico y particularmente con el cumplimiento de las tareas académicas; y al no realizar estos esfuerzos por parte de los y las docentes se afectará el desarrollo de niveles superiores de comprensión lectora, tal como lo señalan Carvajal et al:

Se hará difícil para ellos el cumplimiento de tareas académicas tales como la elaboración de ensayos, reseñas, resúmenes, la comprensión de enunciados sobre problemas, tanto técnicos como humanísticos y su consecuente resolución, la comprensión de argumentaciones sobre problemas teóricos, la discusión de los propios programas curriculares de sus cursos y la misma planificación de las actividades y estrategias de aprendizaje basados en los contenidos de los programas de las asignaturas. Mucho más se dificulta la correcta expresión de las ideas, la crítica objetiva a las situaciones de aprendizaje y el ordenamiento de las ideas complejas para construir conocimiento. (Carvajal et al., 2010, p.139)

De esta manera, cuando falla la comprensión lectora, el estudiantado siente que no ha comprendido, no ha podido comunicarse apropiadamente y su producción escrita carece de fundamentos académicos. De ahí derivan los 
Revista Estudios, (37), 2018.

Diciembre 2018-Mayo 2019

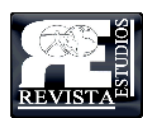

ISSN 1659-3316

Argüello Scriba Sol

Regueyra Edelmann María Gabriela

fracasos y muchas veces la deserción y otra serie de problemas en nuestra universidad, temas que ha tratado con profundidad la investigadora argentina Ezcurra (2011).

\section{Cada disciplina una "cultura"}

La Universidad constituye una cultura como un todo, y cada disciplina es una cultura particular con su objeto de estudio, sus códigos lingüísticos, su propia manera de estructurar el pensamiento y de realizar nuevas propuestas, aspectos que deben ser aprehendidos por la población estudiantil, al respecto Castro y Sánchez, docentes de la Universidad de Tlaxcala en México, comentan:

En el contexto universitario, leer y escribir son prácticas generalmente asociadas con la construcción y divulgación de saberes y, en particular, con la reflexión intelectual crítica respecto a esos saberes. Es claro que no se trata de actividades mecánicas que puedan aprenderse de la noche a la mañana; para analizar y reflexionar sobre las cuestiones de la naturaleza, los problemas del hombre o de la sociedad hacen falta herramientas intelectuales y habilidades de expresión y comunicación que sólo se adquieren en la interacción y el diálogo cotidianos con los miembros de las comunidades científicas y disciplinares que se ocupan de trabajar las distintas parcelas del conocimiento. (Castro y Sánchez, 2013, p. 484)

Ante tales afirmaciones, estamos de acuerdo en que cada disciplina es una cultura y la población docente debe enseñarla "alfabetizando" la población estudiantil. Para lograr este propósito, consideramos al igual que Carlino que esta propuesta debe estar contenida en la política de las instituciones de educación superior, para que la población docente cuente con el aval institucional y los recursos requeridos; un ejemplo de esto, menciona Carlino, se encuentra en la Universidad Tecnológica de Victoria, en Melbourne, que en sus políticas: “ ...estatuye la necesidad de que cada materia se ocupe de la alfabetización

\section{(c) (i) (2)}

La Revista Estudios es editada por la Universidad de Costa Rica y se distribuye bajo una Licencia Creative Commons Atribución-NoComercial-CompartirIgual 3.0 Costa Rica. Para más información envíe un mensaje a 
Revista Estudios, (37), 2018.

Diciembre 2018-Mayo 2019

ISSN 1659-3316

Argüello Scriba Sol

Regueyra Edelmann María Gabriela

académica de sus estudiantes. Y exige que la enseñanza de estas competencias para el estudio y la comunicación” . (Carlino, 2003, p. 413)

Estudios como los de Fernández, et al. (2012) parten de la premisa de que toda disciplina comunica un lenguaje el cual es utilizado por una comunidad inmersa en esa disciplina, un sistema que implica premisas, conceptos y dominio de una materia que a su vez, plantea retos semánticos, lingüísticos y léxicos distintivos y característicos, además de un contexto, elementos que obligan a la población estudiantil a alfabetizarse: a aprender a leer y a escribir. De esta manera, en palabras del autor:

Pero, si tenemos en cuenta que las disciplinas están constituidas por prácticas discursivas propias, involucradas en un sistema conceptual y metodológico, aprender una materia no consiste solo en adquirir sus nociones y métodos sino en manejar sus modos de leer y escribir característicos. (Fernández et al.,2012, p. 27)

Más adelante complementan que:

...ingresar en una comunidad disciplinar determinada implica apropiarse de sus usos instituidos para producir e interpretar sus propios textos, y eso solo puede hacerse con la ayuda de los miembros de esa cultura disciplinar, que muestren y compartan con los recién llegados las formas de interpretación y producción textual empleadas en su dominio de conocimiento. (Fernández et al., 2012, p.28)

El lenguaje en el que se expresa una disciplina es empleado en cada curso y en cada carrera; este tiene sus variantes y se aprende-aprehende, debe ser enseñado en las aulas y no pretender que sea adquirido por los estudiantes sin esfuerzo y conciencia del docente universitario, así como lo explican Estienne y Carlino:

\section{(c) (i) (2)}

La Revista Estudios es editada por la Universidad de Costa Rica y se distribuye bajo una Licencia Creative Commons Atribución-NoComercial-CompartirIgual 3.0 Costa Rica. Para más información envíe un mensaje a 
En la universidad, los textos han de ser leídos de formas específicas según los objetivos que se propone cada cátedra. El programa de una materia permite, a quien sabe interpretarlo, discernir qué se considera importante en la bibliografía. En ocasiones, los docentes proveen orientación pero en algunos casos se trata sólo de una indicación puntual. (Estienne y Carlino, 2004, p.5)

Esto se observa cuando estas especialistas afirman que "Los estudiantes que ingresan a la universidad provienen de una cultura lectora diferente, donde las prácticas de lectura son otras, los objetivos, las reglas y los materiales son distintos" (Estienne y Carlino 2004,p.4). Y continúan: "En los textos universitarios de las ciencias sociales, aparece gran cantidad de información no explícita en el material de lectura, que debe ser inferida por el lector" (Estienne y Carlino 2004, p.4). Por lo tanto, no se puede realizar la enseñanza de una materia sin comprender que la población estudiantil no es capaz de responder a las solicitudes o expectativas de la población docente, porque no han adquirido: "las reglas sobre cómo leer los textos, cada cátedra propone una forma de abordaje particular. Los profesores esperan que los alumnos realicen un recorrido de los textos o de los autores, en función de aquello que se quiere trabajar. Pero muchas veces los alumnos no logran cumplir con estas expectativas" (Estienne y Carlino 2004, p. 5).

Por ello, la población docente debe brindar las herramientas téoricometodológicas al estudiantado durante la enseñanza de cualquier materia de la malla curricular.

\section{(C) $(00$}

La Revista Estudios es editada por la Universidad de Costa Rica y se distribuye bajo una Licencia Creative Commons Atribución-NoComercial-CompartirIgual 3.0 Costa Rica. Para más información envíe un mensaje a 
Revista Estudios, (37), 2018.

Diciembre 2018-Mayo 2019
ISSN 1659-3316

Argüello Scriba Sol

Regueyra Edelmann María Gabriela

\section{El docente universitario y la alfabetización académica}

Ante la preocupación que manifiestan docentes universitarios cuando afirman que los estudiantes ahora no leen y no entienden porque no estudian, y de la tendencia generalizada de echarle la culpa a las bases que ofrece la segunda enseñanza, las especialistas Estienne y Carlino proponen, de manera muy clara, que: "A nuestro juicio, la queja docente debe ceder paso a la enseñanza: en este caso, a la enseñanza de una práctica lectora. $Y$ enseñar prácticas no es lo mismo que enseñar conceptos". (Estienne y Carlino, 2004, p. 3)

Y agregan:

... los alumnos sí leen, pero leen como pueden o como saben hacerlo. Y esto suele ser distinto a cómo los docentes esperamos que lean. Intentaremos mostrar que nuestras expectativas como profesores (no cumplidas por los alumnos) tampoco aparecen claramente manifiestas. Es decir, los docentes esperamos que los alumnos lean de determinada manera pero no enseñamos a hacerlo y entonces nos quejamos pensando que simplemente no lee. (Estienne y Carlino, 2004, p.3)

Carlino propone, al igual que otros especialistas, que la comprensión lectora y la expresión escrita universitarias se adscriben tanto a un espacio discursivo y retórico como conceptual de una disciplina concreta, en la cual, el estudiante al mismo tiempo que aprende los contenidos, debe aprender a interpretar y a desarrollar un discurso crítico. En palabras de la citada autora:

I. Una disciplina es un espacio discursivo y retórico tanto como conceptual (Bogel y Hjortshoj, 1984, p.14). ¿Cabe entonces al docente desentenderse de cómo los alumnos leen y escriben los contenidos de su asignatura, es decir, cómo interpretan y producen su discurso)? ¿Acaso ocuparse de ello no es parte de enseñar esa asignatura?

\section{(C) $(0 \bigcirc$}

La Revista Estudios es editada por la Universidad de Costa Rica y se distribuye bajo una Licencia Creative Commons Atribución-NoComercial-CompartirIgual 3.0 Costa Rica. Para más información envíe un mensaje a 
II. Leer y escribir son instrumentos claves para adueñarse de las nociones de un campo de estudio: para acceder a ellas en toda su complejidad, para pensarlas poniéndolas en relación con los conocimientos previos y para repensarlas estableciendo vínculos entre sí; en síntesis, para elaborarlas, comprenderlas y hacerlas propias. (Carlino, 2004, p. 6)

Los mayores esfuerzos para apoyar a la población estudiantil universitaria que enfrenta dificultades con la lectoescritura han estado orientados a ofrecer cursos de redacción y ortografía separados de la formación disciplinar; este es un primer esfuerzo que permite el desarrollo de habilidades y destrezas en la escritura académica; sin embargo, no es suficiente para lograr que la población estudiantil se apropie de la cultura disciplinar, como lo afirman Castro y Sánchez, desde su experiencia en la Universidad de Tlaxca, México:

Llevó mucho tiempo reconocer que las prácticas letradas académicas están directamente relacionadas con los estilos cognitivos que caracterizan a cada área del saber, y que se necesitan más de que cursos de ortografía para acercar a los estudiantes universitarios a los requerimientos y exigencias de la interaccción comunicativa especializada. (Castro y Sánchez, 2013, p. 484)

Por lo tanto en el desarrollo de cada materia, además de enseñar contenidos de la disciplina,debe crear los medios para que la población estudiantil logre apropiarse de la cultura disciplinar con su espacio retórico particular, al repecto Bogel y Hjortshoj (1984), citados por Carlino, mencionan que:

Aprender los contenidos de cada materia consiste en una tarea doble: apropiarse de su sistema conceptualmetodológico y también de sus prácticas discursivas características, ya que "una disciplina es un espacio discursivo y retórico, tanto como conceptual". (Carlino, 2002, p. 2)

\section{(c) (i) (9) (2)}

La Revista Estudios es editada por la Universidad de Costa Rica y se distribuye bajo una Licencia Creative Commons Atribución-NoComercial-Compartirlgual 3.0 Costa Rica. Para más información envíe un mensaje a revistaestudios.eeg@ucr.ac.cr. 
Revista Estudios, (37), 2018.

Diciembre 2018-Mayo 2019
ISSN 1659-3316

Argüello Scriba Sol

Regueyra Edelmann María Gabriela

La universidad debe reconocer que para lograr formar profesionales con capacidades para leer y construir textos académicos, se debe contar con:

Un control de normas de diversa índole (gramaticales, ortográficas, etcétera) pero, además, un conocimiento de las pautas genéricas, de la estructura retórica de los textos a leer o escribir; también se necesita el reconocimiento de estas prácticas interactivas en las que nuestro sentido del mundo (interno o externo), de la realidad (cotidiana o científica) y de nosotros mismos (como individuos o como miembros de una comunidad) se origina en nuestra relación con otros usuarios de lenguaje, a través del diálogo sucesivos, variados e interminables. (Castro y Sánchez, 2013, p. 488)

Estas afirmaciones nos hacen comprender que todo estudiante universitario escribe y esta escritura implica la reelaboración de conocimientos adquiridos, de interiorización de los mismos, aparte de un estilo y lenguaje común perteneciente a una comunidad concreta. La Universidad de Costa Rica ha dado los primeros pasos en crear cursos de Expresión escrita y también de Expresión oral en la Escuela de Filología, Lingüística y Literatura para las poblaciones estudiantiles; sin embargo, con excepciones de algunas carreras que los han incorporado en sus mallas curriculares, estos esfuerzos están separados de los objetos de estudio de las disciplinas académicas.

En la universidad, desde cada disciplina, se encuentra un tipo de escritura: la argumentativa, según lo explican Goyes y Klein (2012, p.7), de la siguiente manera: "escribir textos argumentativos en la universidad implica que el estudiante pase de la mera opinión a explicitar una postura soportada por hechos, razones, pruebas que avalen, apoyen o soporten un planteamiento, una tesis"; y continúan: "...sólo escribiendo textos argumentativos es posible reconocer la manera de pensar, la manera como el autor relaciona los conocimientos adquiridos 0 , si se

\section{(C) $(00$}

La Revista Estudios es editada por la Universidad de Costa Rica y se distribuye bajo una Licencia Creative Commons Atribución-NoComercial-CompartirIgual 3.0 Costa Rica. Para más información envíe un mensaje a 
quiere, con la escritura verificamos qué tanto somos propietarios de un saber o productores de conocimiento". (Goyes y Klein, 2012, p. 8).

De esta manera, estos autores reafirman que la comprensión lectora y la producción escrita son destrezas que deben ser aprendidas y por lo tanto enseñadas en las distintas disciplinas. $Y$ agregamos que la solución no está en pretender que la Segunda Enseñanza solucione el problema o aporte las herramientas necesarias para mantenerse con éxito en la Universidad, ya que son ámbitos académicos distintos, con diferentes exigencias .

Para favorecer la permanencia y el éxito de la población estudiantil en la Universidad se debe, además de enseñar el léxico pertinente a una disciplina, descifrar e interpretar, o mejor dicho traducir un texto propio de su carrera; y desarrollar la escritura "argumentativa", es decir: construir argumentos que sustenten una tesis o hipótesis, no solo "narrar" procesos investigativos sino sustentarlos.

Dos disciplinas que desde sus orígenes se han encargado del estudio y la enseñanza del discurso son la Filología y la Filosofía, uno desde la Retórica y otro desde la Lógica, respectivamente. Aún, hoy en día, la Filosofía estudia la palabra desde sus bases lógicas para apegarse a principios de verdad como también para desarrollar el pensamiento crítico. Por su lado, la Filología, con la Retórica, se encarga de estudiar la palabra, el discurso, en fin de la comunicación por medio del lenguaje, oral y escrito.

\section{Retórica clásica y el estudio de la argumentación académica}

La Retórica y la argumentación tienen su origen en la Antigüedad clásica. Estas disciplinas se denominaban "arte (ars en latín) o técnica (texné en griego)", y para su enseñanza se dividían en Retórica, Gramática y Filosofía. Especialmente, la Retórica, denominada "el ars bene dicendi et ars bene scribendi" (Cicerón, II.5)

\section{(c) (i) (2) (2)}

La Revista Estudios es editada por la Universidad de Costa Rica y se distribuye bajo una Licencia Creative Commons Atribución-NoComercial-CompartirIgual 3.0 Costa Rica. Para más información envíe un mensaje a revistaestudios.eeg@ucr.ac.cr. 
o el arte de escribir y hablar bien; profundizaba en las habilidades que debía desarrollar tanto el orador como el escritor. En estas escuelas, se estudiaban todas las posibilidades argumentativas del lenguaje, considerando que este es esencialmente plurisignificativo, es decir metafórico, tal como explica Antonio López Eire (2005, p.6), quien en su trabajo titulado La naturaleza retórica del lenguaje, afirma que "el lenguaje es esencialmente metafórico", esto quiere decir que nos expresamos a través de palabras con múltiples significados, que dependen de diferentes contextos, intencionalidades, épocas.

La Retórica es una de las disciplinas más antiguas de Occidente, surgió en Grecia por razones prácticas en Siracusa (s. IV-V a.C.), desde este contexto, etimológicamente, la palabra retórica está relacionada con el orador o rétor que desde su argumentación proponía un "pacto" ante los jueces, el cual si era suficientemente persuasivo se convertía en ley o decreto del pueblo. Históricamente, la retórica se convierte en la base de la democracia griega. Por lo tanto, esta nace como el arte de la persuasión ante una asamblea, tal como lo explica López Eire (1998):

Según la una y la otra, surgieron rétores, "oradores públicos", "políticos", que, bien ante la asamblea o bien ante el tribunal de jurados, hablaban persuasivamente a sus conciudadanos ahormando sus discursos a los sentimientos y las actitudes del sufrido pueblo, que, eliminados los tiranos, se había convertido ya por fin en juez y árbitro de su propio destino. (López Eire, 1998, p.69)

Los griegos elaboraron los primeros tratados analíticos y expositivos de retórica (Rethoriké de Aristóteles), con los cuales intentaron descubrir las bases reales de la comunicación. Así por ejemplo, Gorgias (s.IV-V a.C.), el orador, empezó también a comprender el uso de las figuras del lenguaje como la aliteración, asonancia, antítesis, paralelismo; lo que demuestra que la creación literaria, desde sus orígenes, formó parte de la retórica o al menos nacen juntas y 
ISSN 1659-3316

Argüello Scriba Sol

Regueyra Edelmann María Gabriela

van a ir de la mano durante siglos y no solo en la Antigüedad Clásica. Las figuras literarias pueden, y de hecho le suministran al texto literario, un carácter persuasivo o demostrativo, según sea el caso. Y esto nos lleva a afirmar que la Retórica desde sus orígenes nace no solo para la apropiada y correcta expresión oral, sino también crea reglas de la composición escrita.

Por ello, Ann M. Gill y Karen Whedbee (Van Dijk, 2012, p.157), en su escrito titulado Retórica, exponen sobre las diversas definiciones de la retórica, las cuales inician a partir de Aristóteles, s. III a.C., en su libro Retoriké o Retórica, el libro I,1355b26 (trad. 1999) afirmó que esta es: la capacidad de discernir, en cualquier caso dado, los medios disponibles de persuasión. En conceptos modernos se puede traducir que todo lenguaje y por ende "discurso", escrito o no, pretende convencer de una posición o postura, por ello es persuasivo y para lograr su objetivo da argumentos. Por su lado, Cicerón, s.l, en su texto El orador, en el Libro II, 5 (trad.1991), orador y abogado latino, dijo que la retórica es: el arte del bien decir, es decir, con conocimiento, habilidad y elegancia.

Algunos especialistas modernos como Campbell (1988, p.1) quien afirma que este arte es el descubrimiento de argumentos apropiados para demostrar un asunto determinado, así como la hábil organización de los mismos. Bryant (1972, p. 26) explicó que esta técnica trata de: ajustar las ideas a las personas y las personas a las ideas, citados por Gill y Whedbee (2008, p.233). Todos ellos giran sobre un mismo asunto y que implica tanto la capacidad argumentativa oral y escrita; por ello, López Eire la organiza de la siguiente manera:

Establecida esta diferencia entre los puntos de vista vigentes antaño y los actuales, la verdad es, pese a todo, que el área de estudio de la moderna retórica es el mismo que el de la retórica originaria y primigenia, es decir, la retórica griega, que ya desde su nacimiento, concebida como el arte de la persuasión mediante el lógos (voz que, como es bien sabido, significa en griego antiguo tanto "argumento" como "palabra"), dedicaba a ambos componentes

La Revista Estudios es editada por la Universidad de Costa Rica y se distribuye bajo una Licencia Creative Commons Atribución-NoComercial-CompartirIgual 3.0 Costa Rica. Para más información envíe un mensaje a 
ISSN 1659-3316

Argüello Scriba Sol

Regueyra Edelmann María Gabriela

del discurso sus esfuerzos, sometiéndolos a estudio teórico y a observación minuciosa y atenta encaminada a la fijación de reglas o normas uniformes teórico-prácticas resultantes de la experiencia. (López Eire, 1995, p. 871)

De esta manera, en la Antigüedad grecoromana, se enseñaba a reflexionar, razonar y expresar las ideas persuasivas mediante la razón-palabra (lógos), "bajo esa dualidad privativa del lenguaje humano, empleada, justamente, en esas dos dimensiones, a saber: la dimensión del lógos en cuanto a significado, o sea: "argumento", y la del lógos en cuanto forma significante provista de significación, o sea: "palabra” ( López Eire, 1995, p. 871).

Hoy en día, se continúan utilizando estas técnicas retóricas en la llamada Nueva Retórica, ya que todo escrito académico es "argumentativo" que conlleva el propósito de convencer por medio del lenguaje, habilidad que debe ser enseñada en el ámbito académico universitario. Tal como lo propuso en su momento el mismo Aristóteles, citado por López Eire, quien establece que la retórica es un "arte" que se aprehende:

... una disciplina teórico-práctica, las labores de observación y teorización que competen el arte de la elocuencia son tres: la obtención de medios de persuasión para fabricar con ellos argumentos, actividad por la cual la retórica es un arte correlativo, homólogo y paralelo a la dialéctica, la disposición ordenada de los materiales obtenidos de esa primera función y ya trasladados al discurso, y el estilo en que éste debe aderezarse y hacerse realidad, una vez compuesto, mediante la dicción, que, junto con la acción oratoria, son los dos factores de la ejecución del discurso oral. (López Eire, 1995, p. 872)

Así los aspectos aristotélicos que componen un discurso son: la recopilación de los medios a los que llamará pisteis o pistas, que podemos traducir como "pruebas", en un lenguaje más cercano al nuestro el orador-escritor argumentaba por medio de ejemplos (pruebas) o argumentos, lo suficientemente 
cercanos al auditorio o al lector para convencerlo de "su verdad". Así como la utilización de una gramática, un estilo, una disposición del discurso que contemplaba la psicología del auditorio, lo que se llega a denominar en el siglo XX, la teoría de la recepción.

Para demostrar una tesis y que sea aceptada por los receptores, Aristóteles propone:

Ethos o carácter del orador y/ escritor: el orador debe tomar en cuenta el éthos de la comunidad para mantener una postura de imparcialidad que favorecerá la aceptación de la propuesta. Es decir que toma en consideración el conjunto de rasgos, valores, costumbres que conforman el carácter o la identidad de la comunidad discursiva a la que se dirige.

Pathos o emoción: toda comunicación conlleva sentimientos y genera emociones; por lo que el emisor del texto debe tomar en cuenta los sentimientos que puede generar el discurso en el receptor.

Logos: el discurso debe contener argumentos razonados que defiendan la tesis propuesta, con el objetivo de convencer al receptor.

Y Gorgias (s. IV-V a.C.), el rétor griego, propuso el decoro como un cuarto elemento en la composición de un discurso oral o escrito. Este refiere a la adaptación del discurso a variables extrínsecas, tales como la situación, el público y la ocasión del discurso; por lo que se debe considerar la elección del momento oportuno para hablar o permanecer en silencio, así como las palabras que se dicen y el modo de decirlas. En el discurso escrito, la sincronización interna, el flujo de ideas, el ritmo del lenguaje, las variaciones del tono de la voz, para crear una prosa vívida e internamente coherente (Gill, Wedbee, 2008, pp.233-279).

Los aportes anteriores se refieren a la elaboración de un discurso o un texto. Por lo tanto, en el caso de la lectura, se deben descubrir la tesis con sus argumentos, lo cual es posible según Cicerón (s. I a.C.), si se cuenta con un texto "bueno" y "claro", el cual fue elaborado cumpliendo los siguientes pasos:

\section{(c) (i) (9) (2)}

La Revista Estudios es editada por la Universidad de Costa Rica y se distribuye bajo una Licencia Creative Commons Atribución-NoComercial-CompartirIgual 3.0 Costa Rica. Para más información envíe un mensaje a 
Invención: la etapa inicial de la composición, es descubrir todos los argumentos posibles que pueden aportarse en apoyo de una tesis. Una vez que los argumentos están acumulados se ordenan, identificando los más contundentes y se organizan en una estructura convincente.

Disposición: llamada también organización. Explica los modos efectivos de organizar los argumentos en una introducción, cuerpo y conclusión del discurso o texto.

Elocución: se concentra en expresar las ideas y argumentos en un lenguaje claro y vívido, aquí se contempla el uso de las figuras literarias.

Memoria: es el desarrollo de las técnicas de memorización para recordar ideas y el lenguaje del discurso.

Pronunciación: estrategias verbales y no verbales para pronunciar un discurso de manera eficaz, donde se aprende a modular la voz, el tono, así como los gestos y movimientos.

Todos estos aportes de la Retórica clásica en la producción y estudio de un texto académico han sido la base para las propuestas actuales de análisis del discurso, sin desmerecer el uso de este "arte" como tal en la actualidad académica. En la Universidad, el aprendizaje de estas técnicas tienen validez para la organización y composición de trabajos de diversa índole con un estilo claro y preciso, de esta manera la población estudiantil universitaria y docente tendría menos dificultades para realizar su labor.

Por lo tanto, el conocimiento y la aplicación de la Retórica aportan las bases teóricas así como, posibles métodos en el arte de escribir y comprender textos.

\section{Estudios modernos del lenguaje}

Al seguir el desarrollo histórico de los distintos abordajes sobre los estudios del lenguaje, a partir del S.XIX, con el descubrimiento del sánscrito por los occidentales, surgen los métodos comparativos del estudio de la lengua y en consecuencia la aparición de la Lingüística, separándose de la Filología, según lo

\section{(c) (i) (-)}

La Revista Estudios es editada por la Universidad de Costa Rica y se distribuye bajo una Licencia Creative Commons Atribución-NoComercial-CompartirIgual 3.0 Costa Rica. Para más información envíe un mensaje a 
Revista Estudios, (37), 2018.

Diciembre 2018-Mayo 2019

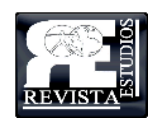

ISSN $1659-3316$

Argüello Scriba Sol

Regueyra Edelmann María Gabriela

explica el estudioso costarricense Arturo Agüero Chaves, quien, en su trabajo titulado "Origen y desarrollo de la lingüística", explica:

...la diferencia esencial entre la filología y la lingüística estriba en los propósitos de una y otra ciencia: el filólogo estudia el lenguaje como un medio, para la interpretación y fijación de los textos, distintos para comprender el lenguaje y sus formas de comunicarse y el contexto en que se desarrolla (Agüero, 1985, p.7).

Surgen pronto las distintas escuelas lingüísticas en el siglo XX y hoy en día, los estudios lingüísticos tienen diferentes ramas o especialidades como la psicolingüística, la sociolingüística, etnolingüística, por citar algunas, incorporando el lenguaje cotidiano de las diferentes esferas de la vida humana que no había sido considerado en los estudios de la Retórica clásica.

Entre otros estudios, se encuentra la propuesta de Mijail Bajtin (1895-1975), crítico literario, teórico y filósofo del lenguaje ruso, quien propuso la distinción entre el discurso monológico y dialógico, lo mismo que la polifonía o las distintas voces en el texto y la noción del carnaval en la novela. Se destacó además por los aportes en el estudio del discurso, hablando de géneros discursivos y tomando en cuenta el entorno o ideología en que se ubica el texto o discurso. En sus propias palabras:

El vínculo orgánico e indisoluble entre el estilo y el género se revela claramente en el problema de los estilos lingüísticos o funcionales. En realidad los estilos lingüísticos o funcionales no son sino estilos genéricos de determinadas esferas de la actividad y comunicación humana. En cualquier esfera existen y se aplican sus propios géneros, que responden a las condiciones específicas de una esfera dada; a los géneros les corresponden diferentes estilos. Una función determinada (científica, técnica, periodística, oficial, cotidiana) y unas condiciones determinadas, específicas para cada esfera de la comunicación discursiva, generan determinados géneros, es decir, unos tipos temáticos, composicionales y estilísticos de enunciados determinados y relativamente estables. El estilo está indisolublemente vinculado a determinadas unidades

La Revista Estudios es editada por la Universidad de Costa Rica y se distribuye bajo una Licencia Creative Commons Atribución-NoComercial-CompartirIgual 3.0 Costa Rica. Para más información envíe un mensaje a 
temáticas $\mathrm{y}$, lo que es más importante, a determinadas unidades composicionales; el estilo tiene que ser con determinados tipos de estructuración de una totalidad, con los tipos de su conclusión, con los tipos de la relación que se establece entre el hablante y otros participantes de la comunicación discursiva (los oyentes o lectores, los compañeros, el discurso ajeno, etc.). (Bajtin, 1982, p.5)

Como se evidencia en la cita anterior, Bajtin se separa de la clasificación clásica de género aristotélico, y aporta la noción de los géneros discursivos; reconoce que cada uno estos tiene un contenido temático y un léxico particulares, esto contribuye a la comprensión de que cada disciplina académica desarrolla géneros discursivos particulares y pertinentes a su objeto de estudio, conformando una cultura académica.

Su propuesta contribuye junto con las nuevas investigaciones lingüísticas y la Nueva Retórica al estudio de cómo se "construyen y se comprenden" los diferentes discursos o textos.

\section{Nuevos aportes a la creación y comprensión del discurso}

Sumado a la Retórica clásica, los estudios lingüísticos del lenguaje y la noción bajtiniana de los distintos géneros discursivos, la lingüística moderna aporta nuevos enfoques sobre el empleo y comprensión del discurso, denominada la Nueva Retórica, en la cual se unen otras disciplinas como la teoría de la argumentación (Eemeren, Grootendorst, Jackson, Jacobs) (Van Dijk, 2012, p. 208), quienes dicen:

What is Argumentation?

Argumentation uses language to justify or refute a standpoint, with the aim of securing agreement in views. The study of argumentation typically centers on one of two objects: either interactions in which two or more people conduct or have arguments such as discussions or debates; or texts such as speeches or editorials in which a person makes an argument (O'Keefe, 1977). An adequate theoretical approach to argumentation should have something to 
say about both the process of argumentation and the arguments produced in that process.

Cuya traducción es:

¿Qué es la Argumentación?

La argumentación utiliza el lenguaje para justificar o refutar una tesis, con el objetivo de lograr un acuerdo en puntos de vista. El estudio de la argumentación típicamente se centra en uno de dos objetos: o interacciones en las cuales dos o más personas conducen o tienen argumentos tales como discusiones o debates; 0 textos tales como discursos o editoriales en los que una persona propone un argumento (O'Keefe, 1977). Un enfoque teórico adecuado para acercarse a la argumentación debe tener algo que decir sobre el proceso de argumentación y los argumentos producidos en ese proceso (Traducción de las autoras del presente trabajo).

Así la argumentación (o teoría de la argumentación) también se refiere al estudio del proceso de la comunicación textual. Esta es un campo interdisciplinario de estudio y una preocupación central de los investigadores en las disciplinas de la lógica, la dialéctica y la retórica. Puede ser aplicado a los estudios no solo del uso del lenguaje, sino también en la contextualización de todo texto.

A nivel operativo, la argumentación es el proceso de formar razones, justificar creencias y sacar conclusiones con el fin de influir en los pensamientos, acciones de otros; definitivamente, lo importante es la comunicación humana y cómo se lleva a cabo. Su implementación aporta una metodología conceptual en la construcción de los géneros disciplinares y cómo comprenderlos.

La construcción y comprensión de los géneros discursivos académicos conlleva el aprender a argumentar, a crear argumentos producto de la investigación, planificación y evaluación de los materiales recopilados que sostengan un planteamiento, tesis, hipótesis y demás; tal como reflexionan Araya y Roig (2014), cuando lanzan la pregunta sobre qué es argumentar, así: 
Revista Estudios, (37), 2018.

Diciembre 2018-Mayo 2019
ISSN 1659-3316

Argüello Scriba Sol

Regueyra Edelmann María Gabriela

En relación con el término argumentar, Weston (2000, p.11) se refiere a este como el conjunto de razones o de pruebas en apoyo de una conclusión. Particularmente esta actividad mental exige más que la producción de una serie de afirmaciones sobre un postulado u opinión, pues requiere de un proceso de análisis que de una $u$ otra forma permita fundamentar, comparar, contrastar, debatir o reelaborar un precepto (Araya, Roig, 2014, p.169).

Esta teoría permite concebir la evaluación y la corrección de textos escritos como partes de un mismo proceso de aprendizaje de la composición de géneros disciplinares, con el cual los y las estudiantes aprenden a evaluar su propio crecimiento intelectual y adquieren una reflexión crítica de su labor académica. Permite también a los y las docentes guiar a los alumnos en el desarrollo de la expresión personal (Parodi, 2000, p. 152).

\section{El enfoque comunicativo}

Entre las otras aproximaciones a los estudios del discurso o géneros discursivos, se encuentra el enfoque comunicativo, relacionado con los estudios sociocognitivistas o lingüística cognitiva, cuya mirada integra varias disciplinas como la psicolingüística. Proponen que el lenguaje es una adquisición social y no únicamente personal, este se desarrolla en un contexto específico, independiente del espacio y tiempo históricos en el que se establezca la comunicación, se puede entender tomando en cuenta las intervenciones discursivas y cambiantes de la relación lingüística entre las personas. Y como lo explica Parodi (2008), están relacionados con la concepción integral y pluridimensional de los géneros académicos, porque los géneros discursivos tienen como eje primordial de análisis la dimensión cognitiva del legnuaje, tal como Parodi (2008, 2003, 2005a) lo explica en su trabajo Géneros del discurso escrito: hacia una concepción integral desde una perspectiva sociocognitiva:

\section{(c) (†) (-)}

La Revista Estudios es editada por la Universidad de Costa Rica y se distribuye bajo una Licencia Creative Commons Atribución-NoComercial-CompartirIgual 3.0 Costa Rica. Para más información envíe un mensaje a 
El asunto tiene que ver con los principios ontológicos y epistemológicos de nuestra concep- ción de ser humano y de lenguaje y, por ende, de nuestra concepción integral y muldimensional de los géneros. Estos principios son cruciales para explorar una teoría de los géneros académicos y profesionales y para una alfabetización disciplinar especializada. Entonces, desde nuestra visión psico-socio-discursiva del lenguaje (Parodi, 2003, 2005a), en que un sujeto hablante/escritor y uno oyente/lector desempeñan un rol central (Parodi, 2007a, 2008a), los géneros se articulan de modo integral desde un enfoque socioconstructivista -al menos- en tres dimensiones: cognitiva, social y lingüística. (Parodi, 2008, p.19)

El objetivo de la enseñanza de la lengua con el enfoque comunicativo consiste en identificar las competencias lingüísticas como: ¿de qué se habla?, ¿cuál es el momento?, ¿el lugar?, ¿quiénes son los interlocutores propicios? y ¿cuáles las rutinas comunicativas? El carácter integrador del enfoque comunicativo comprende: la lingüística gramatical, textual o discursiva, la sociolingüística, estratégica, mediática o simbólica y literaria.

Con este enfoque, en el ámbito académico, se han propuesto cambios en la formulación de programas de la enseñanza de la lengua, promoviendo la creatividad en el uso de las reglas gramaticales, lo mismo que en las convenciones comunicativas. En la educación superior, esta metodología favorece el desarrollo de nuevos discursos disciplinarios e interdisciplinarios.

La competencia lingüística, según Noam Chomsky, desde la lingüística generativa transformacional llamada también lingüística cognitiva, es el conjunto de reglas lingüísticas que lleva interiormente el hablante, conformada por los conocimientos verbales que le permiten entender un número infinito de enunciados lingüísticos, además de la fonología, la morfología, la sintaxis y el léxico, en fin lo que se llama gramática. A esta propuesta se le suma el saber emplear el lenguaje con propiedad en diversas situaciones que se presentan

\section{(c) (i) (2)}

La Revista Estudios es editada por la Universidad de Costa Rica y se distribuye bajo una Licencia Creative Commons Atribución-NoComercial-CompartirIgual 3.0 Costa Rica. Para más información envíe un mensaje a 
Revista Estudios, (37), 2018.

Diciembre 2018-Mayo 2019

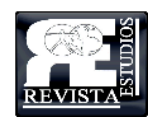

ISSN 1659-3316

Argüello Scriba Sol

Regueyra Edelmann María Gabriela

diariamente en los diversos ámbitos personales y académicos, a lo que Parodi (2008) Ilama la competencia comunicativa.

Así según Parodi (2008), la dimensión lingüística cohesiona las otras dos dimensiones, ya que la comunicación constituye su eje, por lo que propone el término de constructos cognitivos en vez de géneros discursivos, porque:

Ahora bien, es muy cierto que cada sujeto va construyendo sus conocimientos en interacción con otros sujetos y en contextos que demandan instrumentos discursivos diversos, pero no es menos cierto que ese conocimiento, elaborado a través de procesos ontogenéticos, se almacena en la memoria de los lectores/escritores y hablantes/oyentes en un formato representacional complejo, aún no totalmente determinado. (Parodi, 2008, pp. 21-22)

A esto se suman los modelos de situación de van Dijk y Kintsch y luego el modelo de contexto (Parodi, 2008, p.22), "ambos ofrecen mejor comprensión y explicación del modo de operar cognitivamente de los géneros discursivos" (Parodi, 2008, p.22). Definitivamente, el estudio del funcionamiento, formulación y comprensión de los distintos discursos académicos para la enseñanza y aprendizaje en las diversas disciplinas en la universidad, se ven complementados con el método comunicativo, donde toda construcción comunicativa puede considerar otros aspectos aparte de la dimensión del conocimiento, eje central del ámbito universitario.

Aspecto que nos lleva a valorar el bagaje cultural con el que los y las estudiantes asisten a la universidad, cuando Parodi plantea que:

... a partir de conocimientos elaborados socioconstructivistamente y que se almacenan y se activan desde diversos tipos de memorias. De este modo, la dimensión lingüística es la que permite la construcción cognitiva en su interacción con el contexto social externo. Esta concepción integral da cuenta de una visión más amplia y refleja la multidimensionalidad del concepto género. (Parodi, 2008, p.23)

\section{(C) $(00)$}

La Revista Estudios es editada por la Universidad de Costa Rica y se distribuye bajo una Licencia Creative Commons Atribución-NoComercial-CompartirIgual 3.0 Costa Rica. Para más información envíe un mensaje a 
Revista Estudios, (37), 2018.

Diciembre 2018-Mayo 2019
ISSN 1659-3316

Argüello Scriba Sol

Regueyra Edelmann María Gabriela

Y más adelante agrega: ... destaco la dimensión cognitiva de los géneros porque con ello busco apuntar el rol central del ser humano como sujeto hablante/escribiente y oyente/lector dentro de un proceso de comunicación muy dinámico y participativo (Parodi, 2008, p.23). Construcción dada como parte de todo un proceso continuo desde los niveles primarios hasta llegar a la universidad, la construcción del lenguaje influye definitivamente en el desarrollo de cómo se alfabetiza la población estudiantil, los límites y dificultades en la comprensión de los géneros discursivos universitarios.

A modo de síntesis, no hay que olvidar que el lenguaje tiene múltiples matices, no existe aún un ser humano que plantee una "verdad absoluta", podemos hablar de aproximaciones a la verdad por medio de la palabra. Hoy en día, la Retórica aporta bases para la argumentación académica, puesto que propone el ordenamiento del texto, la organización de las ideas, la recepción de estas, los múltiples matices del lenguaje, aspectos que son complementados con los diversos estudios del discurso, entre estos la Neoretórica y que se sintetiza en la propuesta de la alfabetización académica, que reconoce a cada disciplina como un campo de comunicación, oral y escrita, en torno a su propio objeto de estudio en contextos y momentos particulares.

\section{(c) (i) (2)}

La Revista Estudios es editada por la Universidad de Costa Rica y se distribuye bajo una Licencia Creative Commons Atribución-NoComercial-Compartirlgual 3.0 Costa Rica. Para más información envíe un mensaje a 
Revista Estudios, (37), 2018.

Diciembre 2018-Mayo 2019

\section{Referencias bibliográficas}

Aristóteles. (1999). Retórica. Madrid: Editorial Gredos.

Argüello, S., Regueyra, G. (2015). Superando mitos, sobre la comprensión lectora en la población estudiantil universitaria. Revista Káñina. Universidad de Costa Rica: en prensa.

Agüero, A. (1985). Origen y desarrollo de la lingüística. Editorial de la Universidad de Costa Rica, San Pedro, Montes de Oca.

Araya, J., Roig. J. (2014). La producción escrita de textos argumentativos en la educación superior. Editorial de la Universidad de Costa Rica, San Pedro, Montes de Oca: Revista de Lenguas Modernas, № 20, 2014 / 167-181 / ISSN: 1659-1933

Bajtín, M. (1998) Estética de la creación verbal. México: Siglo XXI.(traducida del ruso al español por Tatiana Bubnova) Recuperado http://www.internet.com.uy/arteydif/GRUPO INVESTIGA/PDF/BAJTIN\%20c ap.\%20Géneros\%20Discursivos.pdf. [ Consulta:setiembre y octubre, 2017]

Carlino, P. 2002. ¿Quién debe ocuparse de enseñar a leer y a escribir en la universidad? Tutorías, simulacros de examen y síntesis de clases en humanidades. Argentina: Universidad de Buenos Aires, CONICET.

. 2003. Alfabetización académica: un cambio necesario, algunas alternativas posibles comunicación libre en el tercer encuentro. La Universidad como Objeto de Investigación, DPTO. De sociología. Argentina: Universidad de la Plata.

\section{(C) $(00$}

La Revista Estudios es editada por la Universidad de Costa Rica y se distribuye bajo una Licencia Creative Commons Atribución-NoComercial-CompartirIgual 3.0 Costa Rica. Para más información envíe un mensaje a revistaestudios.eeg@ucr.ac.cr. 

. 2004. De que modos incentiva en nuestras Instituciones La Responsabilidad por como se Lee y Escribe en la Universidad/IFD. Argentina: Universidad de Buenos Aires, CONICET. . 2004. El Proceso de Escritura Académica: Cuatro dificultades de la Enseñanza Universitaria. Argentina: Universidad de Buenos Aires . 2005. Representaciones sobre la escritura y formas de enseñar en la Universidad de América del Norte. Argentina: Representaciones sobre la escritura y formas de enseñar en la Universidad de América del Norte. . 2005. La Escritura en la Investigación. Argentina: Universidad de San Andrés, Argentina. . 2006. Escribir, leer y aprender en la universidad Una introducción a la alfabetización académica. .2013. Alfabetización Académica Diez años Después.México:Consejo Mexicano de Investigación Educativa, A.C. México. Revista Mexicana de Investigación Educativa Carvajal, P., Trejos, A., Montes de Oca, H. 2010. Competencia lectora de los estudiantes de la Universidad Tecnológica de Pereira y rendimiento académico. Colombia:Scientia et Technica Año XVI, No 44, Abril de 2010. Universidad Tecnológica de Pereira. ISSN 0122-1701.

Castro, M. y Sánchez, M. 2013. La expresión de opinión en textos académicos escritos por estudiantes universitarios . Revista Mexicana de Investigación Educativa, 18(57), 483-506. Recuperado de http://www.redalyc.org/pdf/140/14025774008.pdf [Consulta: junio 2017].

Cicerón. 1997. La invención retórica. Madrid: Editorial Gredos. .1991. El Orador. Madrid: Alianza Editorial. 
Revista Estudios, (37), 2018.

Diciembre 2018-Mayo 2019
ISSN 1659-3316

Argüello Scriba Sol

Regueyra Edelmann María Gabriela

Echauri, E. 1973. Diccionario Latino-Español, Español- latino. VOX. Barcelona:

Bibliograf. Departamento editorial.

Estienne, V., Carlino, P. 2004. De que modos incentiva en nuestras Instituciones

La Responsabilidad por como se Lee y Escribe en la

Universidad/IFD.Colombia: Universidad de Antioquía Medallín, Colombia.

Ezcurra, A. 2011. Igualdad en Educación Superior: Un desafío Mundial. Buenos Aires, Argentina: Editorial UNGS.

Fernández, G., Izuzquiza, M., Ballester, M.A., \& Pía Barrón, M. 2012. Análisis de condiciones didácticas en la enseñanza académica. la lectura y la escritura en la formación de profesores. Recuperado de http://www.ungs.edu.ar/prodeac/wpcontent/uploads/2012/03/Laco-L.-Natale-L.-y-Ávila-M.-2012.-La-lectura-y-laescritura-en-la-formación-académica-docente-profesional.pdf[Consulta: agosto,2017].

Goyes, A., Klein, I. 2012. Alcances, limitaciones y retos en la enseñanza de la escritura en la universidad (Dos casos: Colombia y Argentina).Recuperado de http://www.ungs.edu.ar/prodeac/wp-content/uploads/2012/03/Laco-L.-Natale-L.-yÁvila-M.-2012.-La-lectura-y-la-escritura-en-la-formación-académica-docenteprofesional.pdf[ Consulta: agosto, 2017].

López Eire, A. (S.f.). Retórica y Política. Revista: Retórica, Política e Ideología: Desde la Antigüedad hasta nuestros días. Vol. III. . 1995. Retórica antigua y retórica moderna. Revista Humanitas, Vol XLVII, Universidad de Salamanca, España. 2005. La naturaleza retórica del lenguaje. Revista de Retórica y Teoría de la Comunicación, Añ V, $\mathrm{n}$ ㅇ/9, Junio/Diciembre 2005, www.revistalogo.org., España

\section{(c) (i) (2)}

La Revista Estudios es editada por la Universidad de Costa Rica y se distribuye bajo una Licencia Creative Commons Atribución-NoComercial-Compartirlgual 3.0 Costa Rica. Para más información envíe un mensaje a revistaestudios.eeg@ucr.ac.cr. 
Revista Estudios, (37), 2018.

Diciembre 2018-Mayo 2019

ISSN 1659-3316

Argüello Scriba Sol

Regueyra Edelmann María Gabriela

Gill, A.,Whedbee, K. 2008. "Retórica”. En Van Dijk (ed.): El discurso como

estructura y proceso. Estudios sobre el discurso l: Una introducción

multidisciplinaria: 233- 279. Barcelona: Gedisa.

Parodi, G. 2008. Géneros Académicos y Géneros Profesionales: Accesos Discursivos para Saber y Hacer.Valparaíso, Chile: Ediciones Universitarias de Valparaíso, Pontificia Universidad Católica de Valparaíso

. 2000. La evaluación de la producción de textos escritos argumentativos: una alternativa cognitiva/discursiva. Valparaíso: Revista signos. Versión online http://dx.doi.org/10.4067/S0718-09342000000100012 [ Consulta: octubre, 2017]

La Revista Estudios es editada por la Universidad de Costa Rica y se distribuye bajo una Licencia Creative Commons Atribución-NoComercial-CompartirIgual 3.0 Costa Rica. Para más información envíe un mensaje a revistaestudios.eeg@ucr.ac.cr. 